\title{
Specific Treatment of Bone Metastases in Non-PC Urological Malignancies
}

\author{
Aleksandar Vuksanovic* \\ Clinical Centre of Serbia, Serbia
}

*Corresponding author: Aleksandar Vuksanovic, Clinic of Urology, Clinical Center of Serbia, Belgrade, Serbia.

Received Date: January 30, 2019

Published Date: February 13, 2019

\section{Introduction}

Bones are common site for metastatic development, in fact the third most common site of metastases, right after lungs and liver. This tendency is explained with its microenvironment - specifically bone marrow, that tends to facilitate "thriving" of certain types of metastatic cancer cells, which usually originate from prostate, breast and lung. Prostate cancer in particular has proclivity for development of osseous metastases, where we commonly find that the bones are the only site of its secondary deposits [1].

Bone metastases carry a risk for developing of skeletal related events (SRE), which include: bone fractures (radiological or clinical), need for radiotherapeutical or surgical management, spinal cord compression, hypercalcemia [2]. SREs have detrimental effect on patients, reducing quality of life, mobility, life expectancy, and vastly increase medical expenditures.

Specific treatment of bone metastases has several goals: reduction or complete removal of pain, movement amelioration, increase of survival and prevention of SREs. These can be achieved with different approaches and therapeutic options - locally (surgery, radiotherapy), systemically (bisphosphonates, RANKL inhibitor, radionuclides...), and symptomatically.

In majority of urological publications about bone metastases, focus is usually on prostate cancer [3], which is justifiable due to its impact. Nevertheless, practically all urological tumors can disseminate to the bones, and in some cancers they frequently do so. In this article, we will try to review therapeutic options for urological patients, suffering from the bone metastases, excluding prostate cancer [4].

\section{Urothelial Cancer}

The prevalence of bone metastases in patients with advanced bladder cancer is up to $40 \%$ [5]. In a prospective, randomized, placebo-controlled trial of zolendronic acid in bony metastatic bladder cancer it was shown that bisphosphonates not only reduce and delay SREs, but also improve survival in these patients [6]. Also, we have seen that denosumab was not inferior to zolendronic acid in terms of prevention or delay of SREs in patients with advanced cancer, including urothelial malignancy. It is important to emphasize that this particular study excluded patients with breast or prostate cancer [7]. Currently, there is a Canadian study underway, which has a purpose to evaluate how effective denosumab really is in patients suffering from all urological malignancies, with estimated completion in 2020 [8].

\section{Renal Cell Cancer}

In metastatic RCC bone involvement is present in up to $35 \%$ of the patients, and out of these, even $85 \%$ will develop SREs. Unlike in prostate and urothelial carcinoma, where use of bone protective agents is evidently beneficial, RCC bone deposits do not respond to this treatment options that well. In fact, a large systemic analysis, which included 2749 patients on systemic therapy for RCC, has shown that bisphosphonate therapy did not impact SREs rate or survival $[9,10]$, but did increase renal insufficiency, hypocalcemia and osteonecrosis of the jaw. On the other hand, local therapy was clearly beneficial in selected group of patients. Study that compared metastasectomy/curettage and stabilization vs. biopsy/no surgery in RCC patients with single bone metastasis, showed significantly higher $(\mathrm{p}<0.0066) 5$-year CSS in the surgery group. Also, another publication has shown that single dosed image guided radiotherapy gave high probability of local tumor control for metastatic renal cell cancer, which is generally considered radioresistant [11,12].

\section{Germ Cell Cancer}

Bone metastases in GCC are uncommon with incidence roughly $0.7 \%$ and therefore, no clear recommendations can be given for treatment of these patients [13]. However, in a study that involved 40 GCC patients with bone deposits, they were associated with primary mediastinal tumors, yolk sac component and liver involvement [14]. All patients received HD chemotherapy for GCC, 
and the response rate was $85 \% .10 \%$ had surgical bone resection which revealed necrosis in all cases. 4 patients $(0.9 \%)$ got bone relapses, received no surgery or radiotherapy, and died within one year $[15,16]$.

\section{Penile Cancer}

There is insufficient data on bone metastases in penile cancer patients to make any recommendation for the treatment. In general, distant metastases occur late in the course of the disease. Considering that most of penile cancer cases are squamous cell carcinomas, we can make analogical conclusion that bone protective agents and radiotherapy may be useful in palliative treatment of penile cancer patients, like in other SCCs.

At the end we may conclude that in terms of specific bone metastases therapy, bisphosphonates and denosumab could provide significant benefit in treatment of bone metastases of urothelial cancer, which cannot be stated for renal cell cancer or germ cell cancer. The optimal specific therapy for the former is local surgical or radiotherapy. The latter is present rather seldom, and it can be successfully treated with primary chemotherapy. Penile cancer bone deposits are seen even more sparsely and could be treated with bone protective agents.

\section{Acknowledgment}

None.

\section{Conflict of Interest}

No conflict of interest

\section{References}

1. Vigorita VJ (2007) Orthopaedic pathology. Lippincott Williams \& Wilkins, USA, p. 527

2. Jimenez-Andrade JM, Mantyh WG, Bloom AP, Ferng AS, Geffre CP, et al. (2010) Bone cancer pain. Ann N Y Acad Sci 1198: 173-181.

3. Saad F, Gleason DM, Murray R, Tchekmedyian S, Venner P, et al. (2002) A randomized, placebo-controlled trial of zoledronic acid in patients with hormone-refractory metastatic prostate carcinoma. J Natl Cancer Inst 94(19): 1458-1468.
4. So A, Chin J, Fleshner N, Saad F (2012) Management of skeletal-related events in patients with advanced prostate cancer and bone metastases: Incorporating new agents into clinical practice. Can Urol Assoc J 6(6): 465-470.

5. Coleman RE (2001) Metastatic bone disease: clinical features, pathophysiology and treatment strategies. Cancer Treat Rev 27(3): 165176.

6. Zaghloul MS, Boutrus R, El-Hossieny H, Kader YA, El-Attar I, et al. (2010) A prospective, randomized, placebo-controlled trial of zoledronic acid in bony metastatic bladder cancer. Int J Clin Oncol 15(4): 382-389.

7. Henry DH, Costa L, Goldwasser F, Hirsh V, Hungria V, et al. (2011) Randomized, double-blind study of denosumab versus zoledronic acid in the treatment of bone metastases in patients with advanced cancer (excluding breast and prostate cancer) or multiple myeloma. J Clin Oncol 29(9): 1125-1132.

8. A multicenter randomized double-blind study examining the efficacy and safety of denosumab in combination with first line platinum-based chemotherapy for patients with bone metastasis secondary to metastatic urothelial cancer. NCT03520231.

9. Umer M, Mohib Y, Atif M, Nazim M. (2018) Skeletal metastasis in renal cell carcinoma: A review. Ann Med Surg (Lond) 27: 9-16.

10. McKay RR, Lin X, Perkins JJ, Heng DY, Simantov R, et al. (2014) Prognostic significance of bone metastases and bisphosphonate therapy in patients with renal cell carcinoma. Eur Urol 66(3): 502-509.

11. Fuchs B, Trousdale RT, Rock MG. (2005) Solitary bony metastasis from renal cell carcinoma: significance of surgical treatment. Clin Orthop Relat Res 431: 187-192

12. Zelefsky MJ, Greco C, Motzer R, Magsanoc JM, Pei X, et al. (2012) Tumor control outcomes after hypofractionated and single-dose stereotactic image-guided intensity-modulated radiotherapy for extracranial metastases from renal cell carcinoma. Int J Radiat Oncol Biol Phys 82(5) 1744-1748.

13. Jamal-Hanjani M, Karpathakis A, Kwan A, Mazhar D, Ansell W, et al (2013) Bone metastases in germ cell tumours: lessons learnt from a large retrospective study. BJU Int 112(2): 176-181.

14. Oechsle K, Bokemeyer C, Kollmannsberger C, Mayer F, Berger LA, et al. (2012) Bone metastases in germ cell tumor patients. J Cancer Res Clin Oncol 138(6): 947-952.

15. Silva SC, Wilson C, Woll PJ (2015) Bone-targeted agents in the treatment of lung cancer. Ther Adv Med Oncol 7(4): 219-228.

16. Fairchild A (2014) Palliative radiotherapy for bone metastases from lung cancer: Evidence-based medicine?. World J Clin Oncol 5(5): 845-857. 